\title{
ADESÃO ÀS PRECAUÇÕES UNIVERSAIS: UMA ANÁLISE DO COMPORTAMENTO DE EQUIPE DE ENFERMAGEM'1
}

\author{
Maria Meimei Brevidelli² \\ Ruth E. Assayag ${ }^{3}$ \\ Gilberto Turcato Jr. ${ }^{4}$
}

\begin{abstract}
RESUMO: A possibilidade de aquisição do vírus de imunodeficiência humana (HIV) por profissionais de saúde tornou mais preocupante a questão dos riscos ocupacionais. As precauções universais (PU) surgiram como tentativa de aumentar a segurança do profissional de saúde. No entanto, existe certa resistência por parte dos profissionais de saúde em adotar as medidas de proteção. Os objetivos deste estudo são: 1 . obter u m indicador da adesão da equipe de enfermagem de um hospital geral de São Paulo às precauçőes universais, 2. identificar a percepção dos riscos e os conhecimentos que os profissionais possuem sobre as $\mathrm{PU}$; e 3. apresentar e discutir hipóteses explicativas do comportamento de não-adesão.
\end{abstract}

UNITERMOS: Precauções Universais (PU) - Adesão às PU - AIDS - HIV - Riscos Ocupacionais - Reencape de Agulhas.

\section{INTRODUÇÃO}

Os riscos ocupacionais ligados à aquisição de infecções pelos profissionais de saúde são de particular importáncia tanto por acarretarem danos à saúde do profissional, como por gerarem custos elevados às instituições hospitalares. ${ }^{5}$

O risco de aquisição de infecções sempre suscitou a adoção de medidas preventivas para diminuir a transmissão de agentes infecciosos (bactéria ou vírus) de paciente para paciente e de paciente para o profissional de saúde, cha- madas de técnicas de isolamento. Essas técnicas eram utilizadas toda vez que se suspeitava ou se conhecia o agente infeccioso, caracterizando um sistema diagnóstico-dependente. No entanto, este sistema apresentava pouca eficácia na prevenção de transmissão de infecções carreadas pelo sangue, devido à impossibilidade de conhecer a priori o diagnóstico sorológico do paciente;18. O surgimento do vírus da imunodeficiência humana (HIV) tornou imperativa a revisão desta prática. Segundo afirmam Baraff e Talan2, mais de vinte casos de aquisição ocupacional do HIV por profissionais de saúde já

1 - A versão preliminar deste trabalho foi apresentada no $46^{\circ}$ Congresso Brasileiro de Enfermagem, Porto Alegre, e no $4^{\circ}$ Congresso Brasileiro de Controle de Infeccão Hospitalar, Recife. Agradecemos o parecerista anónimo da Revista Brasileira de Enfermagem pelas proveitosas recomendações para melhoria da versão preliminar deste estudo. Agradecemos também a colaboração do Prof. Dr. Fernando Garcia, que conosco discutiu a metodologia estatística empregada neste trabalho.

2 - Enfermeira da UTI do Hospital Alemão Oswaldo Cruz e mestranda da Escola de Enfermagem da Universidade de São Paulo.

3 - Enfermeira-chefe da CCIH do Hospital Alemão Oswaldo Cruz.

4 - Médico-chefe da CCIH do Hospital Alemão Oswaldo Cruz e professor responsável pela disciplina de doenças infecciosas e parasitárias da Escola Paulista de Medicina, respectivamente.

5 - Segundo Sumner ${ }^{24}$, o custo relacionado a acidentes ocupacionais envolvendo pacientes com hepatite B nos Estados Unidos varia de U $\$ 50,00$ a U $\$ 300,00$ por profissional acidentado, apenas considerando o uso de testes sorológicos e a administração de imunoglobulina. 
estão descritos em literatura, tornando mais preocupante a questão dos riscos ocupacionais ligados à saúde.

As precauções universais (PU) surgiram nesse contexto, como tentativa de aumentar a segurança do profissional de saúde, dada a alta freqüência de exposições a fluídos e secreções ligadas às suas atividades. No entanto, existe certa resistência por parte dos profissionais de saúde em adotar as medidas de proteção (uso de barreiras físicas que evitam o contato com secreções e técnicas corretas de manipulação e descarte de agulhas e objetos cortantes), como relatam alguns estudos: [2], [3], [6], [11] e [17].

\section{RISCOS OCUPACIONAIS COM AIDS E ADESÃO ÀS PRECAUÇÕES UNIVERSAIS}

O vírus da imunodeficência humana (HIV) é transmitido por contato com sangue contaminado decorrente de exposiçăo ocupacional, entre outras possibilidades. Exposiçăo ocupacional se refere a um contato direto com fluidos potencialmente contaminados, durante o período de trabalho, que pode ser prevenido [7]. Além do sangue, outros fluidos orgânicos são considerados potencialmente infectados (FPI): sémen, secreções vaginais, líquor, líqüido sinovial, pleural, pericárdico, peritoneal, amniótico ou fluidos visivelmente contaminados por sangue; [7] e [12]. Devido ao grande número de contatos com sangue e outros fluidos orgânicos, o profissional de saúde está constantemente exposto a aquisiçăo de infecçőes, fato que se tornou mais preocupante com o surgimento da AIDS. A exposição pode ocorrer de três modos distintos:

- por inoculação percutânea, também chamada de parenteral;

- por contato direto com membranas mucosas;

- por contato direto com pele não-íntegra, ou seja, cortada, arranhada ou afetada por dermatites.

A inoculação parenteral é a responsável pela maioria das exposiçőes ocupacionais e acontece freqüentemente por perfuração de agulha contaminada por sangue durante o reencape ou o descarte desta, ou ainda, durante venopunçőes [9] e [10]. São também comuns acidentes com objetos cortantes (bisturi, por exemplo) e com recipientes para o descarte de materiais perfurocortantes. Em 1988, o CDC (Centers For Disease Control) constatou que $89 \%$ das exposiçőes ao HIV resultaram da inoculação parenteral, $6,5 \%$ do contato entre material infectado e pele não-íntegra e 4,5\%, de contato com membranas mucosas [10]. Nos Estados Unidos, aproximadamente 800.000 acidentes com agulhas e outros objetos cortantes acontecem por ano. Desses acidentes aproximadamente $2 \%$ envolvem objetos cortantes contaminados por HIV [1].

A taxa de contaminação por HIV após uma perfuração acidental de agulha foi estimada em $0,4 \%$, ou seja, uma contaminação a cada 250 perfurações; [16] e [20]. Tão ou mais importante quanto esse é o risco de contaminação pelo vírus da Hepatite $B$ (HBV), que está estimado entre $6 \%$ a $30 \%$. Aproximadamente 200 a 300 profissionais de saúde morrem por ano nos EUA, devido a aquisição ocupacional do HBV: [1], [6], [14] e [30]. Apesar do risco de contaminação ocupacional por HIV ser baixo, a mortalidade esperada é de $100 \%$, o que torna claro o fato de que esse risco năo pode ser ignorado. Casos de profissionais de saúde contaminados nos quais năo foram identificados outros fatores de risco que não a inoculação percutânea já estāo descritas em literatura: [2], [10] e [20]. Além desses, três casos de soroconversão para o HIV como resultado de contato direto de sangue com mucosa e pele não-íntegra já foram documentados pelo CDC [5].

Por essas razőes, desde 1987 o CDC recomenda a adoção de uma política de prevenção de infecções carreadas pelo sangue [4], com o objetivo de garantir a segurança do profissional de saúde na realização de atividades predisponentes a exposições ocupacionais. Esta política é conhecida com precauções universias (PU) As precauções universais são direcionadas a todos os profissionais de saúde (médicos, enfermeiros, dentistas, técnicos de laboratório, estudantes) e atingem, também o pessoal da limpeza e lavanderia. As PU recomendam que todos os pacientes sejam considerados poten- 
cialmente infectados e enfatizam que todos os profissionais de saúde devem aderir rigorosamente as recomendaçőes para minimizar o risco às exposições já que este é o único modo de prevenir a transmissão. Elas consistem, essencialmente, em dois tipos de orientações:

- Uso de barreiras ou equipamento de proteção que evitam o contato com FPI;

- Manipulaçăo cuidadosa de agulhas e objetos cortantes.

A adoção da política das precauções universias foi também discutida pela OSHA (Occupation Safety and Health Administration) que é o órgão que padroniza e regulamenta medidas de segurança no trabalho nos EUA. Este órgão estabeleceu um protocolo que define os papéis das instituições de saúde e do profissional na viabilizaçăo do processo [7], [21]. Detalhes para implementação da precauções săo descritos, também, por Hopkins [12].

Apesar do fato de as PU diminuírem os riscos de aquisição ocupacional de infecçőes carreadas pelo sangue e, dessa forma, garantirem maior segurança no trabalho, esta práatica não encontra ainda a aceitação e adesão desejadas como apontam alguns trabalhos. Em estudo realizado no Departamento de Emergéncia do Hospital Johns Hopkins em 1989, onde a prevalência de pacientes com AIDS era de $6 \%$, verificou-se que as PU só eram seguidas em $44 \%$ do total de intervenções realizadas pelos profissionais de saúde. Em pacientes com sangramento importante, a adesăo era ainda menor, de $19,5 \%$. Outro estudo, realizado no Departamento de Emergência da Universidade de Miami [11], onde a prevalência do HIV era de $19 \%$ dos casos, constatou que a adesão às PU era de apenas $16 \%$. Mesmo na vigência de procedimentos invasivos, tais como intubação endotraqueal ou inserção de catéteres torácicos, a adesão era inferior a $40 \%$. Willy et alli [28] realizaram estudo abrangendo um grupo de 1784 enfermeiras obstetras que verificou a ocorrência de um grande número de exposições ocupacionais vivenciadas por estas profissionais $(50 \%$ relataram respingos de sangue e líquido aminiótico na face). Os autores observaram, mesmo as- sim, que apenas $55 \%$ relatavam o uso das PU.

Vários estudos procuram esclarecer as razões que explicam a não-adesão às precauçőes universias. O estudo de Willy et alli [28] demonstrou que existe conhecimento insuficiente $e$ interpretação incorreta das PU. Isto porque se observou que certos profissionais tinham a crença de estar cumprindo as PU, mais revelavam uma baixa adesão às práticas de lavagem de mãos e uso de luvas para venopunções. Questionadas sobre as razões de tal comportamento, $79 \%$ das enfermeiras afirmaram que as PU interferiam no relacionamento enfermeira-paciente, $67 \%$ que as PU diminuiam a destreza manual e $38 \%$ consideravam desnecessário o emprego de precauçőes. Tempo insuficiente para colocar o equipamento de proteçăo adequado e a interferéncia na habilideade de realizar procedimentos de emergência são citados por Kelen et alli [15] como razões para a năo utilização das PU.

Duas das questões mais preocupantes, contudo, são a declaração de alguns profissionais de saúde sobre o desconhecimento da existência das PU e a percepção de que elas são desnecessárias, mesmo após a instituiçăo de programas educacionais. Este fato pode indicar que ou o risco não é seriamente considerado, ou os profissionais consideram que o risco é muito baixo. Esta interpretação está muitas vezes vinculada à crença de que as precauções năo garantem a completa segurança do profissional. Muitas enfermeiras relatam que o uso de luvas por longos períodos pode causar irritação de pele, ou que aumentaria o risco de infecçőes. Alguns médicos acreditam que a proteção de luvas năo é perfeita, pois freqüentemente encontram sangue em suas mãos após retirar luvas usadas em atendimentos de emergência; [2].

Não obstante, Kaczmarek et alli[13] relacionou a influência do medo ao uso de luvas quando observou uma maior adesão prática em estados onde a prevalência da AIDS é elevada.

\section{OBJETIVOS E METODOLOGIA}

Pela discussão apresentada até o momento, percebemos que a não-adesão às precau- 
çơes universias tornou-se uma questão preocupante por năo apresentar índices satisfatórios. Motivados por esta questão, este estudo teve como objetivos:

1. Obter um indicador de adesăo às precauçőes universais em um hospital geral da cidade de São Paulo;

2. Analisar o padrăo de comportamento da equipe de enfermagem do mesmo hospital, verificando o conhecimento efetivo das $\mathrm{PU}$, a consistência do sistema de crenças do profissional, a percepçăo dos riscos envolvidos em algumas atividades e a percepção dos benefícios de se aderir às precauções universais; $e$

3. Com base nas informações levantadas, discutir hipóteses alternativas que expliquem o comportamento desses profissionais.

\section{Metodologia}

As precauçőes universias foram implantadas neste hospital em 1987 e, desde então, os profissionais de enfermagem vêm recebendo treinamento e reciclagens periódicas.

Quanto à obtençăo do indicador de adesăo, escolhemos observar somente a obediência com relação a uma das recomendações das PU: a de năo reencapar agulhas. Isso se deve a dois motivos. O reencape de agulhas é reconhecidamente um dos maiores fatores de risco da aquisição ocupacional de infecções carreadas pelo sangue. $E$, principalmente, porque neste hospital a freqüência relativa de acidentes com materiais perfuro-cortantes (ferimentos perfurantes e ferimentos cortantes) foi de $83 \%$ do total de acidentes com material biológico, considerando o período entre julho de 1989 e março de 1994. Entre os ferimentos perfuro-cortantes $20 \%$ foram causados por reencape de agulhas.

A pesquisa foi realizada no més de junho de 1994 e consistiu na contagem das agulhas desprezadas nos recipientes para descarte de objetos perfuro-cortantes. Foram observados 22 recipientes da Unidade de Terapia Intensiva, nos quais se constatou a presença de 1206 agulhas no total. A contagem das agulhas observou as seguintes categorias: (i) agulhas desconectadas das seringas, (ii) agulhas conectadas nas seringas e năo reencapadas; $e$ (iii) agulhas conectadas nas seringas e reencapadas. A distinção entre agulhas conectadas e desconectadas foi necessária pois é prática freqüente neste hospital desconectar as agulhas das seringas ao se administrar medicações endovenosas. Isto porque esse tipo de administração é feito introduzindo a seringa diretamente no dispositivo lateral conectado ao cateter venoso. Nesse caso a agulha não é utilizada e, portanto, consideramos que as agulhas desconectadas das seringas foram desprezadas ainda encapadas.

Observamos, entre as agulhas conectadas, a distinção entre agulhas utilizadas na coleta de sangue para a análise laboratorial, agulhas para administração subcutânea e as demais agulhas utilizadas pela equipe de enfermagem da UTI. As agulhas foram classificadas como de uso laboratorial conforme dois critérios: (i) a marca comercial da seringa a que estava conectada; ou (ii) a presença de sangue no interior da seringa. Fizemos tal distinção com a finalidade de detectar a participaçăo efetiva da equipe de enfermagem na adesão a esta recomendação das PU, uma vez que a coleta de sangue é realizada pelo pessoal do próprio laboratório. As Tabelas 1 e 2 no Anexo I apresentam os resultados.

Para estabelecer a significância estatística dos índices de reencape nas diferentes amostras (seringas de uso laboratorial, subcutáneas e demais, também chamadas de comuns), aplicamos o teste de diferença entre proporções ao nível de significância de $5 \%(p=0,05)^{5}$. Para determinar a significância do estimador de reencape aplicamos o mesmo teste ao nivel de significância de $5 \%$, considerando que o índice de reencape admissível é de $10 \% 6$.

5 - A metodologia estatística empregada neste trabalho está exposta em Vieira [26] e [27].

6 - Winickoff et alli [29] consideram que este é o índice de năo-adesăo satisfatório. Além dos argumentos apresentados pelos autores, podemos afirmar que para nossa pesquisa este valor é razoável, considerando-se as características da equipe de enfermagem: cerca de $90 \%$ de nossa amostra recebeu treinamento em PU, o que constitui razăo suficiente para năo esperarmos um índice de năo-adesăo de $10 \%$. 
A literatura pesquisada indica a existência de alguns fatores que interferem no comportamento dos profissionais de saúde em relação ao cumprimento das PU. Com o objetivo de analisar tais fatores, levantamos duas hipóteses explicativas da adesão à recomendaçăo de năo reencapar agulhas:

- a percepção correta, ou incorreta, dos riscos associados ao reencape;

- o grau de conhecimento efetivo das PU (recomendações e fundamentos).

Para avaliar essas hipóteses elaboramos um questionário que foi distribuído aos profissionais de enfermagem (enfermeiros, técnicos e auxiliares) de três unidades do mesmo hospital (Unidade de Terapia Intensiva, Centro Cirúrgico e Unidade de Enfermagem Intensiva). Essas unidades foram selecionadas partindo-se da premissa de que nelas se concentram pacientes com maior número de procedimentos invasivos, o que indica um maior potencial a exposições ocupacionais envolvendo sangue e outras secreçס̋es.

O questionário é composto por três seções. A primeira busca obter informações gerais a respeito dos participantes, tais como: grau de escolaridade, identificado pela categoria profissional, experiência profissional, conhecimento do conceito de precauções universias e o recebimento de treinamento específico. Além disso, buscamos identificar o nível de exposição ocupacional através da observação da freqüência com que o profissional manipula sangue e outras secreções, com a finalidade de constatar se esse profissionais têm realmente um maior potencial a exposições. A segunda parte do questionário tem por objetivo:

- verificar a auto-avaliação do profissional acerca de seu conhecimento sobre as PU ( se ele o considera completo ou não);

- observar o grau de conhecimento efetivo das PU através da atribuição de uma escala de valores a alguns procedimentos descritos. Ao profissional é solicitado atribuir graus de importância a esses procedimentos conforme a seguinte escala: (0) Cesnessário, (1) importante em algumas situaçőes e (2) importante em qualquer situação.
A terceira parte do questionário tentou analisar a percepçăo individual do risco ocupacional: a expectativa do profissional com relação ao risco de contrair AIDS e Hepatite B após acidentes com agulhas e se ele acredita que pode adquirir infecções no seu trabalho. Observamos também se os profissionais acreditam que as PU trazem algum benefício ou se eles as consideram desnecessárias ou de difícil aplicação. Além disso, algumas das questões pretendem avaliar a consisténcia do conhecimento a respeito das $\mathrm{PU}$. O questionário é apresentado no Anexo II com o devido gabarito.

\section{RESULTADOS E DISCUSSÃO}

Do total de 1206 agulhas observadas nos 22 recipientes para descarte de material pérfurocortante, $84,6 \%$ estavam desconectadas das seringas e apenas $15,4 \%$ encontravam-se conectadas. Entre as agulhas conectadas, $46,8 \%$ estavam reencapadas e $53,2 \%$ não estavam reencapadas. Estes dados indicam que quase a metade das agulhas foram reencapadas, contrariando as recomendações das PU. Isto significa que a adesão às $\mathrm{PU}$, no que tange ao cumprimento da recomendaçăo de não reencapar agulhas, não é satisfatório.

Das 186 agulhas conectadas às seringas, 136 foram utilizadas pela equipe de enfermagem e 50 foram utilizadas na coleta de sangue. Considerando as agulhas empregadas pela equipe de enfermagem, observamos que $50,1 \%$ năo estavam reencapadas e 44,9\% estavam reencapadas. Considerando satisfatório um índice de reencape de $10 \%$, observamos que o índice de reencape da equipe de enfermagem é significativamente maior $(P=0,05)$ que o valor admissível: o valor $Z$ calculado, 8,09 é superior ao valor crítico $Z^{*}=1,96$. Isto implica que podemos refutar a hipótese de que a diferença entre os dois índices (satisfatório é observado) é nula. Estes dados indicam que a adesão da equipe de enfermagem à esta recomendação das PU é, de fato, insatisfatória.

Este baixo índice de adesão ganha relevância, se levarmos em consideração o fato de que parcela significativa da equipe de enfermagem 
tem nível superior (cerca de $40 \%$ ); o pessoal do laboratório tem apenas nível técnico, na sua maioria. A porcentagem de agulhas utilizadas na coleta de sangue que estavam reencapadas é um pouco maior $(48,0 \%)$. Contudo, a diferença no índice de reencape das duas amostras (equipe de enfermagem e equipe laboratorial) não é significativamente diferente de zero ao nível de significáncia de $5 \%$ o valor $Z$ calculado é de menos $1,25 \%$, ou seja, inferior ao valor crítico $Z^{\star}$. Isto indica que năo podemos descartar a hipótese de que o índice de reencape é igual nas duas populações.

Observamos ainda que $32,3 \%$ das agulhas para administraçăo subcutânea estavam reencapadas, enquanto que $67,7 \%$ năo estavam reencapadas. $O$ indice de reencape estimado pela proporção das agulhas para a administraçăo subcutânea reencapadas $(32,3 \%)$ é, também, significativamente diferente do índice admissível de $10 \%$ ao nível de significância de $5 \%$. 0 valor $Z$ calculado $(2,46)$ é superior ao valor crítico de $Z^{*}$. $O$ intervalo de confiança do estimador de reencape indica limites superior e inferior de $40,7 \%$ e $23,9 \%$, respectivamente.

Este dado é importante se considerarmos a possibilidade do profissional reconectar uma agulha ainda encapada à sua seringa, quando esta é utilizada numa administração endovenosa. Muito embora esta prática não seja usual, a obsevação de um caso como este apontaria que o índice de não-adesão fora superestimado, pois se considerou uma agulha reconectada como reencapada. Contudo, não existe a possibilidade deste fato ocorrer com as agulhas utilizadas na administraçăo subcutânea. Portanto, o indice de não-adesão estimado, a partir da observação das agulhas de administração subcutânea, constitui um indicador mais seguro do cumprimento dessa recomendação das precauções universias.

Por fim, cabe destacar que o índice de reencape observado nesta pesquisa (entre $23,9 \%$ e $40,7 \%$ ) é condizente com a experiência internacional. Becker et alli [3], por exemplo, pesquisaram o indice de reencape de agulhas em quatro unidades distintas de quatro instituiçőes. Os autores constataram que das 16 unidades pes- quisadas, 12 apresentavam índices de reencape superiores a $25 \%$, sendo que o índice excedeu $50 \%$ em quatro dessas unidades.

Com relação aos 85 questionários distribuídos aos profissionais da equipe de enfermagem das referidas unidades, 74 foram respondidos, nas seguintes proporçőes: $443,2 \%$ por enfermeiros; $32,4 \%$ por técnicos de enfermagem e $24,3 \%$ por auxiliares de enfermagem. A seguir apresentamos e analisamos separadamente os resultados referentes às características gerais da amostra, à percepção dos riscos ocupacionais e ao conhecimento efetivo das precauçőes universais.

\subsection{Características Gerais da Amostra}

A maioria dos entrevistados, $74,3 \%$, está trabalhando na profissão há mais de 5 anos. O grupo seguinte de profissionais, $20,3 \%$, trabalha entre 2 a 5 anos e somente $5,4 \%$ tem apenas entre 0 e 2 anos de experiéncia profissional; assim, $94,6 \%$ da amostra tem mais de dois anos de profissão. A quase totalidade da amostra estudada declarou conhecer as PU e ter recebido treinamento específico: $98,6 \%$ e $91,9 \%$, respectivamente. As percentagens com relação ao número de vezes por dia que o profissional manipula sangue ou outras secreçőes ficou distribuida da seguinte forma: $60,8 \%$ dos profissionais relataram que manipulam mais de 10 vezes por dia, $16,2 \%$ declararam que manipulam entre 5 a 10 vezes por dia e 20,3\% manipulam entre 3 a 5 vezes por dia. Portanto, os resultados indicam que se trata de uma amostra de profissionais experientes que foram treinados em precauçőes universais e que, como haviamos suspeitado, estão constantemente sujeitos a exposiçőes ocupacionais. Os resultados estão descritos na Tabela 3 do Anexo I.

As 3 categorias profissionais não apresentam características gerais significativamente diferentes. Isto porque as freqüências relativas de enfermeiros, técnicos e auxiliares que têm mais de 2 anos de experiência, que têm treinamento específico em PU e que estão sujeitos a mais de 5 exposições diárias a sangue e outras secreções são estatísticamente iguais. Os valo- 
res $Z$ calculados para as diferenças entre as proporções estão expostos na Tabela 6 do Anexo I. Uma vez que o módulo dos valores $Z$ calculados sempre é inferior ao critico de $Z^{\star}$, não podemos refutar a hipótese de que as 3 populações ( enfermeiros, técnicos e auxiliares) tanham as mesmas características.

Como $91,9 \%$ dos entrevistados receberam treinamento em PU nos últimos 3 anos, aproximadamente, podemos considerar que este percentual indica os níveis satisfatórios de acerto das questões propostas nos questionários. Obviamente, não poderiamos esperar que o grupo de profissionais que não recebeu treinamento em PU conheça e cumpra suas recomendações.

\subsection{Percepção dos Riscos Ocupacionais}

Apenas $13,5 \%$ dos entrevistados estimaram corretamente o risco de se adquirir AIDS no trabalho; o risco estimado é de $0,4 \%$ (entre $1 \%$ e $0 \%$ portanto). Com relação às estimativas de se adquirir Hepatite $\mathrm{B}$, a proporção de entrevistados que estimaram o risco corretamente é ainda menos, de 5,4\%; o risco de adquirir Hepatite B está entre $6 \%$ e $30 \%$. A maioria dos entrevistados, $47,3 \%$ em ambas questões, afirmaram desconhecer as estimativas dos riscos. Portanto, é grande o percentual de profissionais que desconheciam as estimativas do risco. Por outro lado, as diferenças entre as porcentagens de enfermeiros, técnicos e auxiliares que desconhecem as estimativas dos riscos não são significativas: o desconhecimento é homogêneo nas 3 categorias profissionais. A Tabela 6 apresenta os valores $Z$ calculado. O módulo dos valores é sempre inferior a $Z^{\star}$, ou seja, não podemos refutar a hipótese de que as diferenças sejam nulas.

As respostas dadas às perguntas 17,18 e 19 do questionário (ver Anexo II) indicam que 75,7\% da amostra concordou com afirmação de que há risco de adquirir infecções no ambiente de trabalho, $81,1 \%$ concordou com afirmação de que há risco de adquirir AIDS e $87,8 \%$ concordou com afirmação de que há risco de adquirir AIDS ou Hepatite B devido a um acidente com agulha. A Tabela 7 confirma que não há diferen- ças significativas entre as 3 categorias profissionais considerando-se as porcentagens de enfermeiros, técnicos e auxiliares que concordam com as afirmaçס̃es 17, 18 e 19. Por outro lado do total de entrevistados, apenas $17,6 \%$ discordaram da afirmação $17,12,2 \%$ discordaram da afirmação 18 e 5,4\% discordaram da afirmação 19. Tomando por base o valor de $8,1 \%$ como uma porcentagem razoável de discordåncia, observamos que os índices de discordância das questões 18 e 19 não são significativos $(P=0,05)$ : não podemos refutar a hipótese de que as porcentagens estimadas sejam iguais às porcentagens esperadas e aceitáveis. A Tabela 8 no Anexo I apresenta os valores $Z$ calculados.

Com isto, podemos concluir que a percepção do risco de contaminação com HIV e o HBV, particularmente associado a um acidente com agulha, está dentro dos padrões aceitáveis, apesar do fato de que boa parcela dos profissionais desconhece as estimativas de contaminação com HIV e HBV decorrente de acidente com agulha, considerando os dados levantados pelo questionário, a hipótese de que o baixo nivel de adesão seja conseqüência de uma percepção incorreta dos riscos decorrentes do reencape de agulhas não é satisfatória.

\subsection{Conhecimento Efetivo das Precauçōes Universais}

As freqüencias com que os entrevistados declaram ter conhecimento completo e conhecimento incompleto das PU foram de $45,9 \%$ e $41,9 \%$, respectivamente. Dentre os profissionais que consideram seu conhecimento incompleto, observamos que não há significativas deferenças com relação às categorias profissionais: as diferenças entre as porcentagens de enfermeiros, técnicos e auxiliares que consideram incompleto o seu conhecimento não são significativos $(p=0,05)$. A Tabela 6 apresenta os valores $Z$ calculado das diferenças entre três amostras; seu módulo é sempre inferior ao valor crítico $Z^{*}$.

O conhecimento efetivo das precauçőes universias foi verificado através de 22 questões propostas no questionário, envolvendo a aplicação das PU em certos procedimentos. Des- 
sas, 7 questర̋es dizem respeito ao emprego de luvas; questőes 5, 7, 10, 13, 15, 21 e 25. A nona questão diz respeito ao uso de outras barreiras (proteção ocular). As questóes 3 e 24 dizem respeito à lavagem de mãos. As questőes 11 e 14 dizem respeito ao descarte de agulhas. A recomendaçăo de năo se reencapar agulhas, é observado pelas questőes $1,8,22$ e 23 . Por fim, as questóes $2,4,6,12,16$ e 20 caracterizam procedimentos que năo săo pertinentes às precauçőes universias, mas que săo muitas vezes confundidas como tais. Vejamos com detalhes os resultados mais relevantes. As tabelas 4 e 5 do Anexo I apresentam os resultados (número de respostas e percentual).

A totalidade dos entrevistados declarou que o uso para punçóes venosas é importante em qualquer situaçăo (questão 5). Na questão 10 , $97,3 \%$ dos entrevistados declararam que o uso de luvas quando em contato com fezes e urina é importante em qualquer situaçăo. Quanto ao uso de luvas para mudanças de decúbito em pacientes com lesões de pele (questão 13), apenas $81,1 \%$ dos entrevistados declararam que este é um procedimento importante em qualquer situação. Na questão $15,89,2 \%$ dos profissionais declararam que usar luvas e aventais para fazer curativos é importante. Quanto ao uso de luvas para realizar higiene oral do paciente (questão 7), 97,3\% dos profissionais declararam que este é um procedimento importante. Quanto ao uso de proteção ocular (questão 9), apenas $73,0 \%$ da equipe de enfermagem declarou que esse procedimento é importante em qualquer situtação.

A Tabela 7 permite afirmar que o conhecimento das três categorias profissionais é semeIhante, considerando os procedimentos que envolvem o uso de luvas, aventais e óculos de proteção. Isto é, as diferenças das proporções de acertos nas respostas de enfermeiros, técnicos e auxiliares não são significativamente diferentes de zero $(p=0,05)$. A Tabela 8 , por sua vez, permite afirmar que das questőes relacionadas ao uso de barreiras de proteção $(5,10,13,15,7$ e 9), apenas as questőes 9 e13 apresentam indices de acerto significativamente menores que 91,9\%. Podemos considerar incompleto o co- nhecimento das recomendaçס́es referentes ao uso de proteçăo oculare ao uso de luvas para mudança de decúbito em pacientes com lesões de pele.

Nas questőes $3,86,5 \%$ dos entrevistados consideram que lavar as mãos após a retirada das luvas é importante em qualquer situação. Este dado foi corroborado pelas respostas à questăo 24: $89,2 \%$ dos entrevistados discordaram da afirmaçåo "năo é necessário lavar as mãos após retirar as luvas". Novamente, não podemos observar significativas $(p=0,05)$ nas respostas das três categorias, como indica a Tabela 7. Contudo, os índices de acertos nas questőes 3 e 24 são satisfatórias, uma vez que não podemos refutar a hipótese de que sejam iguais ao nivel esperado ( $91,9 \%)$.

As questóes 14 e 11 se referem ao descarte de agulhas: quanto à necessidade de descartar agulhas em recipientes apropriados e de evitar a superlotaçăo dos recipientes, respectivamente, em ambas questőes, a totalidade da equipe de enfermagem considerou tais procedimentos em qualquer situação.

Quanto ao reencape de agulhas (questão 1 ), verificamos que, apesar da maioria $(85,1 \%)$ ter considerado o năo reencape de agulhas importante em qualquer situação, $14,9 \%$ dos entrevistados declararam que este procedimento é importante em algumas situações ou desnecessário. Quando se relaciona o não reencape ao conhecimento do diagnóstico do paciente relativo à AIDS ( questão 8). observamos uma ligeira elevação na porcentagem de entrevistados que consideram esse procedimento importante em qualquer situação $(89,2 \%)$. Esse dado é corroborado pelas respostas à questão $23: 98,6 \%$ da amostra que discordou da afirmação que "é melhor reencapar agulhas quando se sabe que o paciente tem AIDS".

As questőes relacionadas ao reencape de agulhas (1, 8, e 23) não apresentam diferenças significativas com relação aos acerto nas três categorias profissionais analisadas. Os valores $Z$ calculados não permitem refutar a hipótese de que a freqüência de acertos seja a mesma ao nível de significância de $5 \%$, como indica a Tabela 7. Não obstante, o índice de acertos na 
questăo 1 (85,1\%) é significativamente diferente do índice considerado satisfatório $(91,9 \%)$. O módulo do valor $Z$ calculado $(2,130)$ é maior que o valor crítico de $Z$, o que permite refutar a hipotese de que as duas proporçőes sejam iguais. Há uma parcela da população pesquisada que não considera importante a recomendação de nåo reencapar agulhas. Este fato pode explicar, em parte, o baixo indice de adesão à recomendação de năo-reencape.

As questőes 2, 4, 6 e 16 representam procedimentos não preconizados pelas precauçőes universias. Contudo, a maioria dos entrevistados declarou que esses procedimentos săo importantes: na queståo $2,83,8 \%$ da amostra considerou importante usar luvas para administrar medicação em catéteres; na questăo 4, 91,9\% considerou importante usar máscara para preparar medicaçס̌es; na questăo $6,73,0 \%$ considerou importante colocar extensões de nebulizadores-respiradores utilizados em pacientes com AIDS em hipoclorito; e na questão 16, $77,1 \%$ considerou importante servir as refeiçőes de pacientes com AIDS ou Hepatite B com taIheres e copos descartáveis. A questão 12 também representa um procedimento desnecessário. contudo, $58,1 \%$ da equipe de enfermagem considerou importante o conhecimento a priori do diagnóstico sorológico do paciente. Esse dado foi corroborado pelas respostas da questão $20: 62,2 \%$ dos profissionais concordam com a afirmação "eu usaria luvas se soubesse que o paciente tem AIDS".

Com base nos resultados expostos acima, podemos concluir que apenas os procedimentos relativos ao descarte de agulhas (desprezar as agulhas em recipiente apropriado e evitar a superlotação) e ao uso de luvas (para realizar punções venosas e quando em contato com fezes e urina) alcançaram índices aceitáveis de acertos (significativamente maiores que $91,9 \%$ ). As recomendações de não reencapar agulhas (1), usar oculos de proteção ao realizar aspiração de secreções traqueais (9) e usar luvas para mudar o decúbito de pacientes com lesões de pele (13) não alcançaram índices aceitáveis.

Analisamos, também, os índices de acerto nas questões 1,9 e 13 observando se há dife- renças significativas entre o grupo de profissionais que considerou seu conhecimento em PU completo e aquele que considerou incompleto seu conhecimento na questão 1, o grupo que considerou seu conhecimento completo atingiu índice de acerto de $88,2 \%$ e o grupo que considerou seu conhecimento incompleto atingiu índice de acerto de $78,1 \%$ contudo, a diferença entre os dois índices, de $10,1 \%$, năo é significativamente diferente de zero; $Z=1,10$ é inferior ao valor crítico de $Z$. Na questăo 9 , o grupo que considerou seu conhecimento completo atingiu índice de acerto $85,3 \%$ e o grupo que considerou seu conhecimento incompleto atingiu índice de acerto de $90,6 \%$. Novamente, observamos que a diferença entre os dois índices, de $-5,3 \%$, năo é significativamente diferente de zero; $Z=$ 0,67 . Por fim, observamos que na questão 13 o grupo que considerou seu conhecimento completo atingiu índice de acerto de $85,3 \%$ e o grupo que considerou seu conhecimento incompleto atingiu índice de acerto $78,1 \%$. A diferença entre os dois índices, de 7,2\%, não é significativamente diferente de zero; $Z=0,76$. Dessa forma, não podemos afirmar que a crença que os profissionais têm de seu conhecimento sobre PU é condizente com seus acertos, pois aqueles que julgam incompleto seu conhecimento acertam tanto quanto aqueles que julgam seu completo conhecimento.

Tampouco podemos afirmar que o conhecimento dos entrevistados é consistente, ou seja, que as crenças a respeito das $\mathrm{PU}$ são coerentes: houve um percentual significativo de entrevistados que acreditavam em informações contraditórias. A totalidade da equipe de enfermagem acreditava que usar luvas em punçőes venosas é um procedimento importante em qualquer situaçăo; no entanto, $27,0 \%$ acreditava que usar luvas em punções venosas não evita aquisição de infecões. Percebe-se a inconsistência entre as duas crenças, uma vez que, este procedimento não previne a aquisição de infecções, então ele poderia ser considerado supérfluo do ponto de vista das PU. Além disto, 98,6\% da amostra discordou da afirmação de que é meIhor reencapar agulhas quando se sabe que o paciente tem AIDS. Este mesmo percentual de- 
veria, em tese, concordar que năo reencapar agulhas previne a aquisiçăo de AIDS. Contudo, apenas $79,7 \%$ concordou comessa idéia, o que indica uma parcela significativa $(18,9 \%)$ concordou com afirmaçoes contraditórias; essa diferença $* 18,9 \%-8,1 \%)$ é diferente de zero $(p=0,05$, $Z=3,41)$. Isto sugere que há compreensåo incorreta dos fundamentos das precauçסees universias. Essa idéia pode ser corroborada pelo fato de que parte significativa da amostra, cerca de $60 \%$, considerou importante importante o conhecimento a priori do diagnóstico sorológico do paciente, o que caracteriza a antítese das PU.

\section{CONSIDERAÇÕES FINAIS}

Este estudo fornece evidéncias de que muitos profissionais da equipe de enfermagem do hospital pesquisado continuam a reencapar aguIhas, mesmo após receber treinamento especifico em precauőes universais. Apesar de haver constante preocupaçăo por parte da educaçăo em serviço na promoçăo de programas de reciclagem, muitos profissionais demonstraram interpretação incorreta da esséncia e finalidade das PU. A despeito da percepçăo de freqüentes contatos com FPI, uma parcerla significativa dos profissionais năo relacionou o năo reencape de agulhas à prevençăo de aquisiçőes ocupacionais de infecçס̌es carreadas pelo sangue, mesmo considerando aqueles que julgaram completo seu conhecimento das PU. ${ }^{7}$

Os resultados encontrados nesta análise estão em consonância com a pesquisa de Becker et alli [3], que também observou o comportamento dos profissionais com relaçăo à reco- mendaçăo de năo reencapar agulhas. Os autores que o năo-reencape é visto por muitos profissionais como mudança de uma prática já estabelecida, tarefa esta difícil de se alcançar.

Vários estudos demonstram maior eficácia de algumas estratégias para se obter a desejada mudança de comportamento. Programs educacionais utilizando dois métodos informativos (informaçăo passiva e ativa), descritos em Seto et alli [22], foram eficientes na elevaçăo dos índices de adesăo ao năo-reencape de agulhas. Segundo Baraff e Talan [2] e Willy et alli [28], programas informativos que levam o profissional de saúde à conscientizaçăo do risco de aquisiçăo ocupacional de infecçōes influenciam positivamente a adesăo às PU. A influência de um dos membros-chave da equipe sobre os demais, exercendo "poder do especialista", foi considerado por Seto et alli [23] de fundamental importåncia na mudança de comportamento. Não obstante, a utilizaçăo da estratégia de feedback da performance do profissional é a abordagem de maior destaque na literatura devido à sua comprovada eficácia na obtençăo de efetivas mudanças no comportamento, como indicam [8], [19], [25] e [29].

Apesar do treinamento em serviço ser condiçăo sine qua non para qualquer difusão de informaçăo e programa de treinamento, a mudança no comportamento da equipe de enfermagem exige novas abordagens. $O$ presente estudo sugere a importancia de se acessar o conhecimento efetivo do profissional a respeito das precauções universais, a fim de se estabelecer diretrizes para a elaboração de estratégias de intervenção.

7 - No caso dos profissionais que consideram seu conhecimento completo podemos considerar que o índice esperado de acerto é de $100 \%$, mesmo porque todos os profissionais relataram terem recebido treinamento prévio em PU. Neste caso, a diferença entre o índice observado e o esperado é de $11,8 \%$. Essa diferença é significativamente diferente de zero o módulo do valor $Z$ calculado $(-2,14)$ é maior que o valor crítico. 
ABSTRACT: Problems regarding to occupational risk became more apprehensive with the possibility of occupational exposure to HIV by healthcare workers. Universal precautions (UP) emerges as an attempt to increase security of healthcare workers. Nonetheless, the compliance with universal precautions was found to be considerably less than optimal. The purpose of the present paper is: 1. to measure the compliance with universal precautions at a general hospital in São Paulo; 2 . to identify the risk perception and Knowledge about UP of nursing staff, and 3. to discuss altemative hypothesis to explain noncompliance.

KEYWORDS: Universal Precautions (UP) - Compliance With UP - AIDS - HIV - Occupational Risks and Needles Recapping.

\section{REFERÊNCIAS BIBLIOGRÁFICAS}

01. ASSOCIATION FOR PRACTITIONERS IN INFECTION CONTROL. APIC position paper: Prevention of device-mediated blood-borne infections to health care workers. Am J Infect Control. v.21. p. 76-78, 1993.

02. BARAFF, L.J. e TALAN, D.A. Compliance with universal precautions in a university hospital emergency department. Ann Emerg Med, v.18, n.6, p.654-657, 1989.

03. BECKER, M.H. et al. Noncompliance with universal precautions policy: why do physicians and nurses recap needles? Am J Infect Control, v.18, p.232-9,1990.

04. CENTER FOR DISEASE CONTROL. Recommendations for Prevention of HIV Transmission in Health-Care Settings. MMWR, v.36, supplement 2, p.3-18, 1987.

05. CENTER FOR DISEASE CONTROL. Update: human immunodeficiency virus infections in: health-care workers exposed to blood of infected patients. MMWR, v.36, n.19, p.285-289, 1987.

06. COURINGTON, K.R. et al. Universal precautions are not universally followed. Arch Surg. v.126, p.93,96, 1991

07. DECKER, M.D. The OSHA bloodborne hazard standard. Infect Control Hosp Epidemiol, v. 13, p. $407-417,1992$

08. DE VRIES, J.E. et al. AIDS prevention: improving nurses compliance with glove wearing through performance feed-back. J Appl Behav Anal, v.24, p.705-711,1991.

09. FAHEY, B.J. et al. Frequency of nonparenteral occupational exposures to blood and body fluids before and after universal precautions training. Am J Med, v.90, p.145153, 1991.

10. GERSHON, R.M. e Vlahov, D. HIV infection risk to health-care workers. Am Ind Hyg Assoc J. v.51, n.12, p.802-806, 1990.

11. HAMMOND, J.S. et al. HIV, trauma and infection control: universal precautions are universally ignored. J Traụma, v.30, N.5, P.555561,1990 .

12. HOPKINS, C.C. Implementation of universal blood and boby fluid precautions. Infect Dis Clin Nth Am, v.3, n.4, p.747-762,1989.

13. KACZMAREK, R.G. et al. Glove use by healthcare workers: results of a tristate investigarion. Am J Infect Control, v.19, p.222832,1991 .

14. KAZANOWSKI, M.K. A nursing department's response to risks associated with human immunodeficiency virus. Nurs Outlook, v.40, n.1, p.42-44,1992.

15. KELEN, G.D. et al. Human immunodeficiency virus infection in emergency department patients. JAMA, v.262, n.4, p.516522,1989 . 
16. KLEIN, R.S. e Friedland, G.H. Transmission of human immunodeficiency virus type 1 (HIV1) by exposure to blood: defining the risk. Ann Inter Med. v.113, n.10, p.729-730, 1990.

17. LINNEMANN, C.C. et al. Effect of educational programs, rigid sharp containers and universal precautions on reported needlestick injuries in healthcare workers. Infect Control Hosp. Epidemiol, v.12, p.214-249,1991.

18. LYNCH, P. et al. Rethinking the Role of Isolation Practices in the Prevention of Nosocomial Infections. Ann Int Med, v.107, p.243246,1987.

19. MAYER, J.A. et al. Increasing handwashing in a intensive care unit. Infect Control, v.7, N.5,P.259-262,1986.

20. MENDELSON, M.H. HIV infection in healthcare workers: risk and prevention. Mt Sinai J Med. v.57, n.4,p.216-220,1990.

21. PUGLIESE, G. Occupational safety and health administration moves blood-borne pathogen compliance to the front burner. Am J Infect Control, v.20, n.4, p.167$169,1992$.

22. SETO, W.H. et al. Brief report: reduction in the frequency of needle recapping by effective education: a need for conceptual alteration. Infect Control Hosp Epidemiol, v.11,p.194196,1990 .
23. et al. Social power and motivation for the compliance of nurses and housekeeping staff with infection control policie. Am J infect Control, v.19, n.1,p.42-44,1991.

24. SUMNER, W. Needlecaps to prevent needlestick injuries. Infect Control, v.6, n.12, p.495497,1985 .

25.TIERNEY, W.M. et al. Delayed feedback of physician performance versus immediate remainders to perform preventive care. Med. Care, v.24, n.8,p.659-666,1989.

26. VIEIRA, S. Introdução à Bioestatística. Rio de Janeiro: Editora Campus, 1981.

27. Metodologia Científica para Area de Saúde. São Paulo: Editora da Unicamp - Sarvier, 1984.

28. WILLY, M.E. et al. Adverse exposures and universal precautions practices among a group of highly exposed health professionals. Infect Control Hosp. Epidemiol, v.11,n.7,p.351356,1990 .

29. WINICKOFF, R.N. et al. Improving Phsician Performance Trough Peer Comparison Feedback. Med Care, v.22, n.6, p.527-534,1984.

30. YASSI, A. e McGill, M. Determinants of blood and fluid exposure in a large teaching hospital: hazards of the intermittent intravenous procedure. Am J Infect Control, v.19,p.129135, 1991. 
Tabela 1

Agulhas conectadas e desconectadas: número e porcentagem 22 caixas - UTI - Junho de 1994

\begin{tabular}{|c|c|c|}
\hline Agulhas & n. & $\%$ \\
\hline 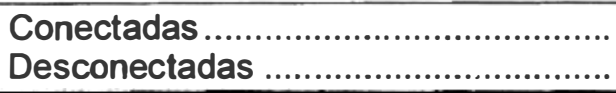 & $\begin{array}{r}1020 \\
186\end{array}$ & $\begin{array}{l}84,6 \% \\
15,4 \%\end{array}$ \\
\hline 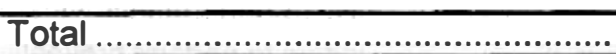 & 1206 & $100 \%$ \\
\hline
\end{tabular}

Tabela 2

Agulhas reencapadas e năo-reencapadas: número e porcentagem 22 caixas - UTI - Junho de 1994

\begin{tabular}{l|cc|cc|cc|cc}
\hline Agulhas Conectadas & \multicolumn{2}{|c|}{ Comuns } & \multicolumn{2}{|c|}{ Laboratório } & \multicolumn{2}{|c|}{ Subcutáneas } & \multicolumn{2}{|c}{ Total } \\
\hline Reencapadas & 51 & $48,6 \%$ & 26 & $52,0 \%$ & 10 & $32,3 \%$ & 87 & $46,8 \%$ \\
Não-reencapadas & 54 & $51,4 \%$ & 24 & $48,0 \%$ & 21 & $67,7 \%$ & 99 & $53,2 \%$ \\
\hline Total & 105 & $100 \%$ & 50 & $100 \%$ & 31 & $100 \%$ & 186 & $100 \%$ \\
\hline
\end{tabular}

Tabela 3 - Unidade de Terapia Intensiva, Unidade de Enfermagem Intensiva • Centro Cirúrgico Caracteristicas gerais e percepclo do risco da amostra: número e porcentagem 74 enfermeiros, técnicos e auxiliares - Junho de 1994

\begin{tabular}{|c|c|c|c|c|c|c|c|c|c|}
\hline \multirow{2}{*}{\multicolumn{2}{|c|}{$\begin{array}{l}\text { Categoria } \\
\text { Número de entrevistados }\end{array}$}} & \multicolumn{2}{|c|}{ Total } & \multicolumn{2}{|c|}{ Enfermolros } & \multicolumn{2}{|c|}{ Tócnicos } & \multicolumn{2}{|c|}{ Auxiliares } \\
\hline & & \multirow{2}{*}{$\begin{array}{c}74 \\
55 \\
15 \\
4 \\
0\end{array}$} & \multirow{2}{*}{$\begin{array}{c}100 \% \\
74,3 \% \\
20,3 \% \\
5,4 \% \\
0,0 \%\end{array}$} & \multirow{2}{*}{$\begin{array}{c}32 \\
21 \\
8 \\
3 \\
0\end{array}$} & \multirow{2}{*}{$\begin{array}{c}43,2 \% \\
65,6 \% \\
25,0 \% \\
9,4 \% \\
0,0 \%\end{array}$} & \multirow{2}{*}{$\begin{array}{c}24 \\
21 \\
3 \\
0 \\
0\end{array}$} & \multirow{2}{*}{$\begin{array}{c}32,4 \% \\
87,5 \% \\
12,5 \% \\
0,0 \% \\
0,0 \%\end{array}$} & \multirow{2}{*}{$\begin{array}{c}18 \\
13 \\
4 \\
1 \\
0\end{array}$} & \multirow{2}{*}{$\begin{array}{c}24,3 \% \\
72,2 \% \\
22,2 \% \\
5,6 \% \\
0,0 \%\end{array}$} \\
\hline Tempo de profissăo & $\begin{array}{l}+ \text { de } 5 \\
(2 \text { a } 5) \\
(0 \text { a } 2) \\
\text { S.R." }\end{array}$ & & & & & & & & \\
\hline Conhece as PU & $\begin{array}{l}\text { sim } \\
\text { năo }\end{array}$ & $\begin{array}{c}73 \\
1\end{array}$ & $\begin{array}{c}98,6 \% \\
1,4 \%\end{array}$ & $\begin{array}{c}32 \\
0\end{array}$ & $\begin{array}{c}100,0 \% \\
0,0 \%\end{array}$ & $\begin{array}{c}24 \\
0\end{array}$ & $\begin{array}{c}100,0 \% \\
0,0 \%\end{array}$ & $\begin{array}{c}17 \\
1\end{array}$ & $\begin{array}{c}94,4 \% \\
5,6 \%\end{array}$ \\
\hline Treinamento em PU & $\begin{array}{l}\text { sim } \\
\text { năo }\end{array}$ & $\begin{array}{c}68 \\
6\end{array}$ & $\begin{array}{c}91,9 \% \\
8,1 \%\end{array}$ & $\begin{array}{c}29 \\
3\end{array}$ & $\begin{array}{c}90,6 \% \\
9,4 \%\end{array}$ & $\begin{array}{c}23 \\
1\end{array}$ & $\begin{array}{l}95,8 \% \\
4,2 \%\end{array}$ & $\begin{array}{c}16 \\
2\end{array}$ & $\begin{array}{c}88,9 \% \\
11,1\end{array}$ \\
\hline Média** & anos & 2.9 & & 3.1 & & 2.8 & & 2.5 & \\
\hline $\begin{array}{l}\text { Vezes por dia que } \\
\text { manipula sangue ou } \\
\text { outras secreçס̄es }\end{array}$ & $\begin{array}{c}(0 \text { a } 3) \\
(3 \text { a } 5) \\
(5 \text { a } 10) \\
+ \text { de } 10 \\
\text { S.R. }\end{array}$ & $\begin{array}{c}1 \\
15 \\
12 \\
45 \\
1\end{array}$ & $\begin{array}{c}1,4 \% \\
20,3 \% \\
16,2 \% \\
60,8 \% \\
1,4 \%\end{array}$ & $\begin{array}{c}1 \\
4 \\
2 \\
24 \\
1\end{array}$ & $\begin{array}{c}3,1 \% \\
12,5 \% \\
6,3 \% \\
75,0 \% \\
3,1 \%\end{array}$ & $\begin{array}{c}0 \\
6 \\
4 \\
14 \\
0\end{array}$ & $\begin{array}{c}0,0 \% \\
25,0 \% \\
16,7 \% \\
58,3 \% \\
0,0 \%\end{array}$ & $\begin{array}{l}0 \\
5 \\
6 \\
7 \\
0\end{array}$ & $\begin{array}{c}0,0 \% \\
27,8 \% \\
33,3 \% \\
38,9 \% \\
0,0 \%\end{array}$ \\
\hline $\begin{array}{l}\text { Auto-avaliação } \\
\text { do conhecimento } \\
\text { das PU }\end{array}$ & $\begin{array}{l}\text { completo } \\
\text { incompleto } \\
\text { nulo } \\
\text { S.R. }\end{array}$ & $\begin{array}{c}34 \\
31 \\
1 \\
8\end{array}$ & $\begin{array}{c}45,9 \% \\
41,9 \% \\
1,4 \% \\
10,8 \%\end{array}$ & $\begin{array}{l}16 \\
13 \\
0 \\
3\end{array}$ & $\begin{array}{l}50,0 \% \\
40,6 \% \\
0,0 \% \\
9,4 \%\end{array}$ & $\begin{array}{c}11 \\
10 \\
0 \\
3\end{array}$ & $\begin{array}{c}45,8 \% \\
41,7 \% \\
0,0 \% \\
12,5 \%\end{array}$ & $\begin{array}{l}7 \\
8 \\
1 \\
2\end{array}$ & $\begin{array}{c}38,9 \% \\
44,4 \% \\
5,6 \% \\
11,1 \%\end{array}$ \\
\hline $\begin{array}{l}\text { Risco aproximado de } \\
\text { contrair AIDS }\end{array}$ & $\begin{array}{c}25 \% \text { a } 10 \% \\
10 \% \text { a } 5 \% \\
5 \% \text { a } 1 \% \\
1 \% \text { a } 0 \% \\
\text { desconhece } \\
\text { S.R." }\end{array}$ & $\begin{array}{c}14 \\
6 \\
5 \\
10 \\
35 \\
4\end{array}$ & $\begin{array}{c}18,9 \% \\
8,1 \% \\
6,8 \% \\
13,5 \% \\
47,3 \% \\
5,4 \%\end{array}$ & $\begin{array}{c}2 \\
4 \\
3 \\
5 \\
16 \\
2 \\
\end{array}$ & $\begin{array}{c}6,3 \% \\
12,5 \% \\
9,4 \% \\
15,6 \% \\
50,0 \% \\
6,3 \%\end{array}$ & $\begin{array}{c}6 \\
1 \\
2 \\
4 \\
10 \\
1\end{array}$ & $\begin{array}{c}25,0 \% \\
4,2 \% \\
8,3 \% \\
16,7 \% \\
41,7 \% \\
4,2 \%\end{array}$ & $\begin{array}{l}6 \\
1 \\
0 \\
1 \\
9 \\
1\end{array}$ & $\begin{array}{c}33,3 \% \\
5,6 \% \\
0,0 \% \\
5,6 \% \\
50,0 \% \\
5,6 \%\end{array}$ \\
\hline $\begin{array}{l}\text { Risco aproximado de } \\
\text { contrair Hepatite B }\end{array}$ & $\begin{array}{c}85 \% \text { a } 50 \% \\
50 \% \text { a } 30 \% \\
30 \% \text { a } 6 \% \\
6 \% \text { a } 1 \% \\
\text { desconhece } \\
\text { S.R. }\end{array}$ & $\begin{array}{c}21 \\
6 \\
4 \\
4 \\
35 \\
4\end{array}$ & $\begin{array}{c}28,4 \% \\
8,1 \% \\
5,4 \% \\
5,4 \% \\
47,3 \% \\
5,4 \%\end{array}$ & $\begin{array}{c}10 \\
2 \\
0 \\
3 \\
16 \\
1\end{array}$ & $\begin{array}{c}31,3 \% \\
6,3 \% \\
0,0 \% \\
9,4 \% \\
50,0 \% \\
3,1 \%\end{array}$ & $\begin{array}{c}6 \\
2 \\
3 \\
1 \\
11 \\
1\end{array}$ & $\begin{array}{c}25,0 \% \\
8,3 \% \\
12,5 \% \\
4,2 \% \\
45,8 \% \\
4,2 \%\end{array}$ & $\begin{array}{l}5 \\
2 \\
1 \\
0 \\
8 \\
2\end{array}$ & $\begin{array}{c}27,8 \% \\
11,1 \% \\
5,6 \% \\
0,0 \% \\
44,4 \% \\
11,1 \%\end{array}$ \\
\hline
\end{tabular}



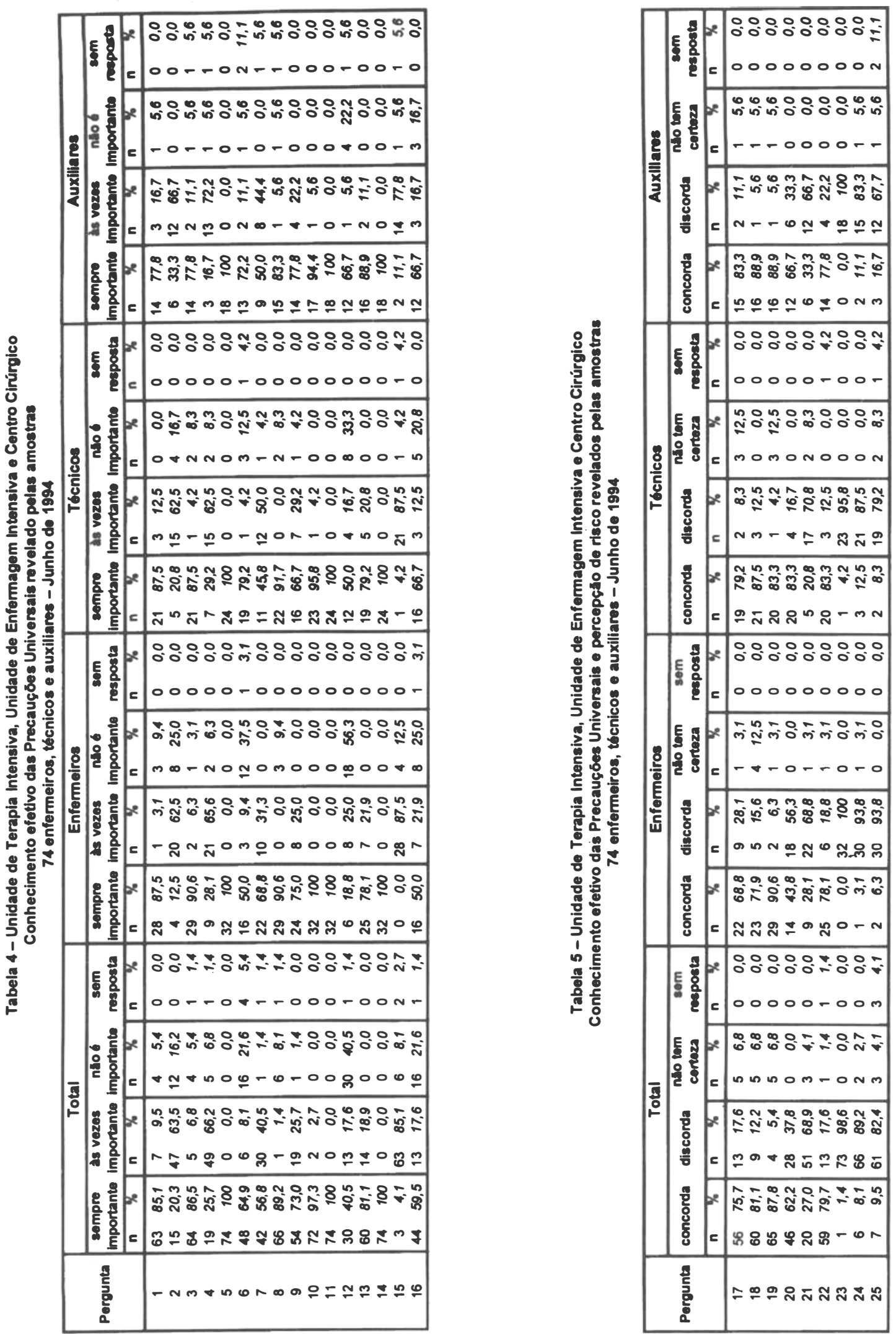
Tabela 6 - Teste de diferenças de proporçós

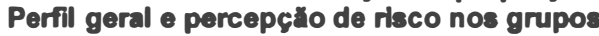
Valores de $\mathbf{Z}$ calculado

\begin{tabular}{|l|r|r|r|}
\hline \multirow{2}{*}{ Característica } & \multicolumn{3}{c|}{ Diferenç entre os grupos } \\
\cline { 2 - 4 } & $\mathbf{1 0 2}$ & $\mathbf{2}$ e 3 & $\mathbf{1}$ e 3 \\
\hline Tempo de profissăo (+ de 2 a.) & $-0,61$ & $-0,37$ & $-0,07$ \\
Recebeu treinamento em PU & 0,24 & 0,25 & $-0,30$ \\
Exposiçăo ocupacional (+ de 5/dia) & 0,23 & 0,37 & $-0,15$ \\
Conhecimento (incompleto e nulo) & $-0,04$ & 0,22 & 0,34 \\
Desconhece a taxa de risco do HIV & $-0,02$ & $-0,11$ & $-0,35$ \\
Desconhece a taxa de risco do HBV & 0,04 & $-0,22$ & 0,08 \\
\hline
\end{tabular}

Grupo 1: enfermeiros • Grupo: técnicos • Grupo 3: auxiliares

Tabela 7 - Teste de diferenças de proporçס̋es Indices de acerto/erro nos grupos Valores de $\mathbf{Z}$ calculado

\begin{tabular}{|l|r|r|r|}
\hline \multirow{2}{*}{ Pergunta } & \multicolumn{3}{|c|}{ Diferenças entre os grupos } \\
\cline { 2 - 4 } & $\mathbf{1}$ e 2 & $\mathbf{2 ~ e ~ 3}$ & $\mathbf{1}$ e 3 \\
\hline 1. Nåo reencape de agulhas & $-0,41$ & 0,41 & 0,47 \\
3. Lavar as máos (após retirar luvas) & $-0,6$ & 0,41 & 0,77 \\
7. Usar luvas (higiene oral) & 1,03 & 0,21 & 1,04 \\
8. Năo reencapar agulhas (HIV+) & $-0,34$ & 0,33 & 0,29 \\
9. Usar oculos de proteçăo & 0,38 & 0,46 & $-0,13$ \\
10. Usar luvas (fezes e urina) & 0,13 & $-0,51$ & 0,18 \\
13. Usar luvas (decúbito) & $-0,24$ & 0,44 & 0,62 \\
15. Usar luvas (curativos) & 0,00 & $-0,14$ & $-0,15$ \\
\hline 17. Risco de infecçóes & 0,58 & $-0,06$ & 0,85 \\
18. Risco de HIV & 1,15 & $-0,35$ & 1,17 \\
19. Risco de HIV e HBV (picada) & 0,40 & 0,07 & $-0,29$ \\
23. Reencapar agulhas (HIV+) & 1,03 & 1,03 & 0,00 \\
24. Lavar as máos (após retirar luvas) & 0,79 & 0,38 & 0,93 \\
\hline
\end{tabular}

Grupo 1: enfermeiros • Grupo: tócnicos • Grupo 3: auxiliares

Tabela 8 - Teste de significâncla dos indlces Índices de acerto/erro nos grupos Valores de $\mathrm{Z}$ calculado

\begin{tabular}{|l|c|c|c|}
\hline \multicolumn{1}{|c|}{ Pergunta } & Observado & Esperado* & $Z^{\text {** }}$ \\
\hline 1. Năo reencape de agulhas & 63 & 68 & $-2,13$ \\
3. Lavar as măos (após retirar luvas) & 64 & 68 & $-1,70$ \\
7. Usar luvas (higiene oral) & 72 & 68 & 1,71 \\
8. Náo reencapar agulhas (HIV+) & 66 & 68 & $-0,85$ \\
9. Usar oculos de proteçăo & 54 & 68 & $-5,97$ \\
10. Usar luvas (fezes e urina) & 72 & 68 & 1,70 \\
13. Usar luvas (decúbito) & 60 & 68 & $-3,41$ \\
15. Usar luvas (curativos) & 66 & 68 & $-0,85$ \\
\hline 17. Risco de infecçరీes & 13 & 6 & 2,98 \\
18. Risco de HIV & 9 & 6 & 1,98 \\
19. Risco de HIV e HBV (picada) & 4 & 6 & $-0,85$ \\
23. Reencapar agulhas (HIV+) & 73 & 68 & 2,12 \\
24. Lavar as máos (após retirar luvas) & 66. & 68 & $-0,85$ \\
\hline
\end{tabular}

- Acerto esperado: 91,9\% (68 entrevistados) - erro esperado: 8,1\% (6 entrevistados);

*- Desvio padrăo: 2.347 